\title{
REAÇÃO A DOENÇAS E PRODUTIVIDADE DE UM CLONE DE MARACUJAZEIRO- AZEDO PROPAGADO POR ESTAQUIA E ENXERTIA EM ESTACAS HERBÁCEAS DE PASSIFLORA SILVESTRE ${ }^{1,2}$
}

\author{
NILTON TADEU VILELA JUNQUEIRA3, DANIEL ANACLETO DA COSTA LAGE ${ }^{5}$, MARCELO FIDELES BRAGA³, JOSÉ \\ RICARDO PEIXOTO ${ }^{4}$, THIAGO ALVES BORGES 5 , SOLANGE ROCHA MONTEIRO DE ANDRADE ${ }^{3}$
}

\begin{abstract}
RESUMO - As doenças causadas por patógenos do solo provocam perdas expressivas em maracujazeiros comerciais. Uma das alternativas de controle dessas doenças seria a utilização de porta-enxertos resistentes. Passiflora nitida é uma das espécies de Passifloraceae que apresentam resistência a essas doenças, mas suas sementes geram porta-enxertos com caules finos e, portanto, incompatíveis com o diâmetro dos garfos da espécie comercial. Este problema pode ser resolvido pela utilização da enxertia em estacas enraizadas ou pela enxertia hipocotiledonar, mas, no Brasil, dados sobre o desenvolvimento e produtividade, em campo, de maracujazeiros enxertados, ainda são escassos. Este trabalho teve como objetivo avaliar a reação a doenças, produtividade e características físicas de frutos de um clone de maracujazeiro-azedo (Passiflora edulis f. flavicarpa) comercial propagado por estaquia, enxertia em estacas herbáceas enraizadas de $P$. nitida (acesso EC-PN 1) e por sementes. As plantas foram cultivadas em um Latossolo Vermelho-Amarelo, onde foram conduzidas em espaldeiras verticais com 1,90 metro em altura, com irrigação por gotejamento. As colheitas foram efetuadas semanalmente, durante 14 meses, e as avaliações das doenças foram efetuadas aos 17; 18 e 19 meses após o plantio. A produtividade das plantas propagadas por estaquia foi o dobro das enxertadas e das propagadas por sementes. Plantas enxertadas e propagadas por estaquia foram menos afetadas pelas doenças.
\end{abstract}

Termos para indexação: controle de doenças, propagação assexuada, porta-enxerto, Passiflora edulis f. flavicarpa, Passiflora nitida, características físicas dos frutos.

\section{REACTION TO DISEASES AND YIELD OF A PASSION FRUIT CLONE PROPAGATED BY CUTTINGS AND GRAFTING ON ROOTED-HERBACEOUS CUTTINGS OF WILD PASSIFLORA SPECIE}

\begin{abstract}
Diseases induced by soil-borne pathogens cause expressive losses in passion fruit crops in Brazil. The use of resistant rootstocks could be an alternative to control these diseases. Passiflora nitida is one of the wild species of Passifloraceae, which have presented resistance to these diseases, but its utilization as seedling rootstock has been limited mainly due to differences of thickness between rootstock and the graft of the commercial cultivars. This problem can be solved by using grafting on rootstock of rooted-herbaceous cuttings and hypocotyledonary grafting, but data about the performance and yield of grafted passion fruit in field conditions are yet scarce in Brazil. The objective of this work was to evaluate the reaction to disease attack, yield and physical characteristics of fruits from a commercial passion fruit clone propagated by rooted cuttings, by grafting on rooted cuttings of a wild P. nitida (source EC-PN 1) and by seeds. The plants were cultivated in a red-yellow latosol with a drip irrigation system and oriented on a vertical espalier of 1,90 meters high. Harvest occurred weekly during 14 months and disease evaluations were carried out at 17, 18 and 19 months after the planting. Plant yields from rooted cuttings were twice greater than those from grafted plants or seedlings. The plants propagated by grafting and rooted cuttings were lesser affected by diseases.
\end{abstract}

Index terms: Disease control, asexual propagation, rootstock, Passiflora edulis f. flavicarpa, Passiflora nitida, fruit physical characteristics.

\section{INTRODUÇÃO}

A baixa produtividade do maracujazeiro no Brasil é devida, em grande parte, a problemas fitossanitários, dos quais as doenças causadas por patógenos do solo constituem-se nos mais importantes em termos de expressão econômica (Chaves et al., 2004; Meletti \& Bruckner, 2001; Menezes et al., 1994). Vários autores (Meletti \& Bruckner, 2001; Ruggiero, 2000; Menezes et al., 1994; São José, 1991; Maldonado, 1991) relatam a necessidade de se usarem porta-enxertos resistentes para controlar a fusariose e a morte prematura. Várias espécies de passifloras silvestres, como Passiflora caerulea, P. nitida, P. laurifólia, alguns acessos de $P$. suberosa, $P$. alata, $P$. coccinea, $P$. gibertii e $P$. setacea, vêm apresentando resistência à morte precoce e a outros fungos do solo (Menezes et al., 1994; Oliveira et al., 1994; Fischer, 2003).

A P. nitida Kunth apresenta grande potencial para utilização em programas de melhoramento que incluam hibridação interespecífica em virtude de sua rusticidade e resistência a vários patógenos e pragas do maracujá (Menezes et al., 1994; Fischer, 2003; Roncatto et al., 2004). É uma espécie amplamente distribuída no território nacional e tem grande capacidade para adaptação em ambientes diversos. Ocorre em todos os estados da região Norte e Centro-Oeste e exemplares já foram coletados no Maranhão, Bahia, Minas Gerais e nordeste do Estado de São Paulo.
No Cerrado, esta espécie pode ser encontrada em tipos fisionômicos distintos, como nas Matas úmidas e Veredas, Matas calcárias ou Matas secas, Matas ciliares, Cerradão e em chapadas com vegetação de cerrado "stricto sensu". Apresenta grande variabilidade quanto ao vigor, tamanho e formato dos frutos. Segundo Junqueira et al. (2005), há grande variabilidade genética entre acessos dessa espécie, originários de diferentes regiões geográficas do País e tipos fitofisionômicos do Cerrado.

No Brasil, ainda são escassas as informações sobre o comportamento de maracujazeiros comerciais enxertados em espécies de passifloras silvestres. As dificuldades encontradas, segundo Meletti \& Bruckner (2001), consistem no fato de os porta-enxertos oriundos de sementes da maioria das espécies silvestres apresentarem o inconveniente de gerar plantas com caules muito finos e, portanto, incompatíveis com o diâmetro dos garfos que são obtidos de plantas adultas. Outro problema consiste na baixa taxa de germinação das sementes e/ou pelo desenvolvimento lento de algumas espécies silvestres, inclusive da P. nitida (Menezes et al., 1994; Meletti \& Bruckner, 2001). Estes problemas dificultam o processo de enxertia, aumentam o custo de produção e o tempo requerido para a formação da muda (Siqueira \& Pereira, 2001). Segundo Chaves et al. (2004) e Nogueira Filho (2003), estes problemas podem ser resolvidos, respectivamente,

\footnotetext{
${ }^{1}$ (Trabalho 096/2005). Recebido: 13/06/2005. Aceito para publicação: 15/02/2006.

2 Trabalho parcialmente financiado com recursos do CNPq

${ }^{3}$ Pesquisadores da Embrapa Cerrados, C.Postal 08223, Planaltina-DF, E-mail: junqueir@cpac.embrapa.br, fideles@cpac.embrapa.br, solange@cpac.embrapa.br ${ }^{4}$ Professor da Faculdade de Agronomia e Medicina Veterinária da Universidade de Brasília, C. Postal 04508, CEP 70910-970, Brasília- DF. E-mail: peixoto@unb.br ${ }^{5}$ Estagiários, bolsistas do CNPq, Faculdade de Agronomia e Medicina Veterinária da Universidade de Brasília
} 
pelo uso de porta-enxertos produzidos a partir do enraizamento de estacas herbáceas das passifloras silvestres ou pela técnica da enxertia hipocotiledonar.

O presente estudo teve como objetivo avaliar, em campo, a reação a doenças, características físicas de frutos e produtividade de um clone de maracujazeiro-azedo propagado por enxertia em estacas herbáceas enraizadas de Passiflora nitida, por estaquia e por sementes.

\section{MATERIAL E MÉTODOS}

O trabalho foi conduzido na Embrapa Cerrados, localizada em Planaltina-DF, a 1.050 metros de altitude, latitude de $15^{\circ} 35^{\prime} 00^{\prime}$, , longitude de $47^{\circ} 35^{\prime} 00^{\prime \prime}$, de agosto de 2002 a abril de 2004, em Latossolo VermelhoAmarelo areno-argiloso, com $\mathrm{pH}=5,7 ; \mathrm{Ca}+\mathrm{Mg}=5,31 \mathrm{meq} / 100 \mathrm{cc} ; \mathrm{P}=$ 9,02 ppm; $\mathrm{K}=122$ ppm e matéria orgânica $=2,6 \%$. Utilizou-se um clone de maracujá-amarelo denominado de GA-2, cuja planta foi selecionada pelo fato de produzir frutos grandes e ter resistência moderada à bacteriose e maior tolerância ao vírus do endurecimento do fruto $(P W V)$. Esse clone foi enxertado em estacas herbáceas enraizadas de $P$. nitida (acesso EC-PN 1) procedente de Itiquira-MT.

O delineamento utilizado foi em blocos ao acaso, com três tratamentos, cinco repetições e cinco plantas úteis por unidade experimental. Os três tratamentos constituíram-se de plantas propagadas por enxertia, estaquia e por sementes obtidas de frutos de polinização não-controlada do clone GA-2.

Para a produção das mudas, as estacas que serviram de portaenxerto, assim como aquelas do clone comercial GA-2, e os garfos (enxertos) foram tirados da parte mediana de ramos de plantas-matrizes propagadas por estaquia, com 12 meses de idade. A enxertia, feita pelo método "garfagem lateral no topo", e os processos para enraizar as estacas foram efetuados conforme descrito por Chaves et al. (2004). As estacas com três nós e um par de folhas no último nó tiveram suas bases imersas durante um minuto em ácido naftaleno acético a $500 \mathrm{mg}$ / L e plantadas em sacos de polietileno de $22 \times 12 \mathrm{~cm} \times 0,01 \mathrm{~mm}$, contendo, em $2 / 3$ de seu volume, um substrato à base de 70 litros de subsolo seco (Latossolo Amarelo de textura média, $\mathrm{pH}=5,3$ e V=36\%) + 30 litros de esterco de gado curtido $+100 \mathrm{~g}$ de calcário dolomítico (PRNT 65\%) + $400 \mathrm{~g}$ de NPK 4 -30-16. Sobre este substrato, adicionou-se uma camada de $8 \mathrm{~cm}$ de substrato comercial Plantmax HT em sua parte superior. As estacas tiveram cerca de 3 a $5 \mathrm{~cm}$ de suas bases enterradas na camada de substrato Plantmax HT umedecido, e mantidas em estufa protegida com sombrite- $50 \%$, com nebulização intermitente a $18 \pm 2^{\circ} \mathrm{C}$ à noite e 25 $\pm 2^{\circ} \mathrm{C}$ ao dia e umidade relativa (UR) de $70 \%$ a $100 \%$. Depois de 30 dias, as estacas foram transferidas para um segundo ambiente de casa de vegetação a $23 \pm 2^{\circ} \mathrm{C}, \mathrm{UR}$ de 60 a $85 \%$, protegida por sombrite $50 \%$, com ventilação e duas regas/dia de 4,0 litros $/ \mathrm{m}^{2}$, durante 15 minutos, sendo uma às $12 \mathrm{e}$ a outra às 15 horas.

As enxertias foram efetuadas aos 55 dias após a coleta e plantio das estacas. Depois da enxertia, os enxertos não foram protegidos com saco de plástico, pelo fato de as estacas estarem em ambiente de casa de vegetação. As mudas enxertadas foram plantadas em campo aos 130 dias após a coleta e plantio das estacas ou 75 dias depois da enxertia. Já as mudas produzidas a partir de sementes e por estaquia foram levadas para o campo aos 90 dias depois do semeio das sementes e da coleta e plantio das estacas no mesmo substrato. A condução das plantas em campo foi feita em espaldeiras verticais com 1,90 metro em altura, com dois fios de arame galvanizado $\mathrm{n}^{\circ} 12$ espaçados de $40 \mathrm{~cm}$. O espaçamento utilizado foi de 2,5 metros entre fileiras e entre plantas, totalizando 1.600 plantas/ha. As covas de $40 \mathrm{~cm}$ x $40 \mathrm{~cm}$ x $40 \mathrm{~cm}$ foram cavadas no mesmo local onde havia restos de maracujazeiros que, em sua maioria, morreram com podridão de raízes provocadas por Fusarium solani, forma assexuada de Nectria haematococa.

A adubação de plantio foi feita com $800 \mathrm{~g}$ de superfosfato simples, 100 g de calcário dolomítico (PRNT 90\%) e 5 litros de esterco de gado, curtido, por cova. As adubações de cobertura, iniciadas aos 45 dias após o plantio, foram efetuadas a cada 30 dias, aplicando-se, por planta, $50 \mathrm{~g}$ de cloreto de potássio, $70 \mathrm{~g}$ de sulfato de amônio e $50 \mathrm{~g}$ de superfosfato simples.

A irrigação foi feita por meio de tubos gotejadores com emissores de vazão de 2,0 litros/hora, espaçados de $50 \mathrm{~cm}$. O sistema era acionado a cada 48 horas por um período de cinco horas. Não foram aplicados defensivos agrícolas, exceto gliphosate nas entrelinhas. As polinizações ocorreram de forma natural.

A colheita, iniciada seis meses após o plantio, foi efetuada a cada sete dias, durante 14 meses. Em cada colheita, determinaram-se o peso e o número de frutos nas parcelas úteis. As avaliações referentes ao rendimento de suco, percentuais de casca, sementes, ${ }^{\circ}$ Brix e doenças foram efetuadas em três lotes de 20 frutos maduros, colhidos ao acaso, em cada parcela, nos meses de janeiro, fevereiro e março de 2004, ou seja, 17; 18 e 19 meses depois do plantio. Determinaram-se a severidade da antracnose (Colletotrichum gloeosporioides) nos frutos maduros e na haste principal até 1,80 metro de altura, a incidência da bacteriose nas folhas, a severidade da virose nas folhas e a incidência de podridão de raízes.

Para avaliar a severidade do vírus do endurecimento $(P W V)$, coletaram-se, ao acaso, 10 folhas em desenvolvimento de brotações novas em ambos os lados da espaldeira. Foi adotada a escala proposta por Novaes \& Rezende (1999), modificada, onde: 1- Resistente: sem sintomas visuais; 1,1 a 1,8 - Suscetível: presença de mosaico leve, sem deformações foliares; 1,9 a 3,0 - Altamente suscetível: folhas deformadas com bolhas e mosaico severo.

Para avaliar a severidade da antracnose nos frutos maduros, adotou-se a seguinte escala: $\mathbf{1 -}$ Resistente: ausência de sintomas; $\mathbf{1 , 1}$ a 2,0 - Moderadamente resistente: até $10 \%$ da superfície do fruto coberta com lesões; 2,1 a 3,0-Suscetível: de $11 \%$ a $30 \%$ da superfície do fruto com lesões; 3,1 a 4 -Altamente suscetível: mais de 30\% do fruto coberto por lesões

Para avaliar a severidade da antracnose na haste principal, determinaram-se as áreas lesadas na haste principal de cada planta até a altura de 1,80 metro e o percentual da área da haste ocupada pelas lesões. A incidência da bacteriose nas folhas foi avaliada pela contagem do número de folhas atacadas em um metro linear de espaldeira, em ambos os lados.

A incidência de podridão de raízes foi determinada pela contagem das plantas com lesões na região do coleto. A presença de $F$. solani nas lesões foi confirmada por isolamentos em meio de cultura BDA e pela análise da massa micelial desenvolvida sobre as lesões.

\section{RESULTADOS E DISCUSSÃO}

O índice de estacas enraizadas de P. nitida aos 60 dias após o plantio destas foi de $100 \%$. O índice de enxertos de maracujá-azedo pegos aos 75 dias após a enxertia variou de $73,3 \%$ a 93,3\%, mas o índice de enxertos brotados variou de $66,7 \%$ a $73,3 \%$.

As plantas propagadas por estaquia produziram frutos com maior massa fresca e em maior número que as propagadas por sementes e por enxertia. Em termos de produtividade ( $\mathrm{t} / \mathrm{ha}$ ), as plantas propagadas por estaquia produziram o dobro das demais (Tabela 1), mas as plantas enxertadas e as propagadas por sementes tiveram produtividades semelhantes.

Não houve diferença estatística entre os métodos de propagação quanto ao ${ }^{\circ}$ Brix e porcentagem de sementes, mas as plantas clonadas e propagadas assexuadamente produziram frutos com maior massa fresca, melhor rendimento em suco e menos casca em comparação com as propagadas por sementes. As plantas enxertadas apresentaram menor porte. Dessa forma, como são clonadas, admite-se que a enxertia retardou o desenvolvimento das plantas, conforme já relatado por Nogueira Filho (2003), trabalhando com enxertia hipocotiledonar em plantas oriundas de sementes de $P$. caerulea, P.alata, $P$. gibertii, $P$. coccinea, $P$. cincinnata, $P$. setacea e $P$. edulis f. flavicarpa. A redução do porte pode ter contribuído para diminuir a produtividade das plantas enxertadas em relação às de estaquia. Menezes et al. (1994) obtiveram 
TABELA 1 - Produtividade e características físicas de um clone de maracujazeiro-azedo (GA-2) propagado por enxertia em estacas enraizadas de Passiflora nitida, estaquia e por sementes. Brasília, 2004.

\begin{tabular}{ccccccccc}
\hline $\begin{array}{c}\text { Métodos de } \\
\text { propagação }\end{array}$ & $\begin{array}{c}\text { Produção } \\
\text { por Planta (g) }\end{array}$ & $\begin{array}{c}\text { Produtividade } \\
\text { estimada (t/ha) }\end{array}$ & $\begin{array}{c}\text { Frutos por } \\
\text { planta }\end{array}$ & $\begin{array}{c}\text { Peso do } \\
\text { Fruto (g) }\end{array}$ & ${ }^{\circ}$ Brix & $\begin{array}{c}\text { Rendimento de } \\
\text { Suco (\%) }\end{array}$ & $\begin{array}{c}\text { Casca } \\
(\%)\end{array}$ & $\begin{array}{c}\text { Semente } \\
(\%)\end{array}$ \\
\hline Sementes & $13.367,9 \mathrm{~b}$ & $21.385,6 \mathrm{~b}$ & $111,4 \mathrm{~b}$ & $123,98 \mathrm{c}$ & $10,8 \mathrm{a}$ & $36,44 \mathrm{~b}$ & $55,9 \mathrm{a}$ & $7,6 \mathrm{a}$ \\
Estaquia & $26.803,5 \mathrm{a}$ & $42.885,5 \mathrm{a}$ & $146,8 \mathrm{a}$ & $182,82 \mathrm{a}$ & $11,8 \mathrm{a}$ & $39,34 \mathrm{ab}$ & $54,2 \mathrm{ab}$ & $6,5 \mathrm{a}$ \\
Enxertia & $13.224,5 \mathrm{~b}$ & $21.159,2 \mathrm{~b}$ & $87,0 \mathrm{~b}$ & $152,46 \mathrm{~b}$ & $11,7 \mathrm{a}$ & $41,17 \mathrm{a}$ & $52,26 \mathrm{~b}$ & $6,6 \mathrm{a}$ \\
\hline C.V. $\%$ & 13,0 & 13,0 & 17,7 & 9,8 & 8,2 & 5,2 & 2,1 & 20,9 \\
\hline
\end{tabular}

Os dados referem-se à média de cinco repetições de cinco plantas, na densidade de 1.600 plantas/ha, no espaçamento de $2,5 \mathrm{~m}$ x $2,5 \mathrm{~m}$.

TABELA 2 - Reação de um clone comercial de maracujazeiro-azedo propagado por enxertia em estacas enraizadas de Passiflora nitida, estaquia e por sementes às principais doenças. Brasília, 2004.

\begin{tabular}{|c|c|c|c|c|c|c|c|}
\hline $\begin{array}{l}\text { Métodos de } \\
\text { Propagação }\end{array}$ & $\begin{array}{l}\text { Virose } \\
\text { Folha }^{1}\end{array}$ & $\begin{array}{l}\text { Bacteriose } \\
\text { nas folhas }{ }^{2}\end{array}$ & $\begin{array}{l}\text { Antracnose } \\
\text { no Fruto }\end{array}$ & $\begin{array}{l}\text { Área da haste lesada } \\
\text { por antracnose }{ }^{3}\left(\mathrm{~cm}^{2}\right)\end{array}$ & $\begin{array}{l}\text { Haste lesada por } \\
\text { antracnose }^{3}(\%)\end{array}$ & $\begin{array}{c}\text { Plantas com a parte } \\
\text { aérea morta }{ }^{4}(\%)\end{array}$ & $\begin{array}{c}\text { Plantas afetadas por } \\
\text { Fusarium solani }{ }^{5}(\%)\end{array}$ \\
\hline Sementes & $2,8 \mathrm{a}$ & $11,9 \mathrm{a}$ & $2,8 \mathrm{a}$ & $822,4 \mathrm{a}$ & $86,1 \mathrm{a}$ & $78,2 \mathrm{a}$ & $64,6 \mathrm{a}$ \\
\hline Estaquia & $1,6 \mathrm{~b}$ & $2,8 \mathrm{~b}$ & $1,5 \mathrm{~b}$ & $440,8 \mathrm{~b}$ & $43,7 \mathrm{~b}$ & $12,8 \mathrm{~b}$ & $20,0 \mathrm{~b}$ \\
\hline Enxertia & $1,6 \mathrm{~b}$ & $2,8 \mathrm{~b}$ & $1,4 \mathrm{~b}$ & $463,6 \mathrm{~b}$ & $52,4 \mathrm{~b}$ & $31,2 \mathrm{~b}$ & $13,2 \mathrm{~b}$ \\
\hline C.V. \% & 7,1 & 12,1 & 9,5 & 17,7 & 17,0 & 26,0 & 26,0 \\
\hline
\end{tabular}

Os dados referem-se à média de cinco repetições de cinco plantas, na densidade de 1.600 plantas/ha, no espaçamento de $2,5 \mathrm{~m}$ x $2,5 \mathrm{~m}$.

(1) Virose na folha e antracnose no fruto: veja escala de notas em Materiais e Método; (2) A incidência de bacteriose nas folhas foi avaliada determinando-se o número de folhas atacadas em um metro linear de espaldeira, em ambos os lados;

(3) A antracnose na haste principal = área da haste lesada $\left(\mathrm{cm}^{2}\right)$ e \% da haste ocupada com lesões até 1,80 metro de altura, determinadas aos 19 meses após o plantio; (4) Plantas com a parte aérea morta devido à antracnose (Colletotrichum gloeosporioides);

(5) Podridão de raízes: Plantas com o coleto e raízes atacadas por Fusarium solani.

bons resultados utilizando $P$. alata, $P$. gibertii, $P$. edulis, P. caerulea* $\mathrm{e}$ Passiflora sp* como porta-enxertos para o maracujazeiro-amarelo, mas não recomendaram a $P$. nitida devido às dificuldades de se obterem mudas e à baixa taxa de sobrevivência dos enxertos.

Quanto à diferença entre as plantas propagadas por sementes e as de estaquia, a maior produtividade destas últimas pode ser explicada pelo efeito da seleção clonal ou pela maior resistência às doenças (Tabela 2). O clone GA-2 foi mais resistente a doenças da parte aérea e do sistema radicular. Já as plantas propagadas por sementes, embora estivessem com maior porte em relação às demais, foram fortemente acometidas pelas doenças (Tabela 2).

O potencial de espécies silvestres como porta-enxerto para maracujazeiro foi confirmado por Terblanche (1986), citado por Menezes et al. (1994). Este autor verificou que o maracujá-roxo (P. edulis) enxertado em $P$. caerulea produziu $41 \%$ a mais que $P$. edulis enxertado em $P$. edulis f. flavicarpa e $74 \%$ a mais que $P$. edulis propagado por sementes (pé-franco). Verificou, também, que a taxa de mortalidade foi de $8 \%$ para P. edulis sobre $P$. caerulea, $66 \%$ para $P$. edulis sobre $P$. edulis $\mathrm{f}$. flavicarpa e de $58 \%$ para plantas oriundas de sementes de $P$. edulis. Este autor não utilizou plantas propagadas por estaquia, mas com base nos seus resultados pode inferir-se sobre a existência de espécies silvestres com maiores graus de compatibilidade com o $P$. edulis f. flavicarpa. Braga et al. (2004) verificaram que plantas de um clone de maracujazeiro, propagadas por enxertia em estacas enraizadas de um híbrido F1 entre P. edulis f. flavicarpa x P. setacea, não foram atacadas por patógenos do solo. A produtividade destas plantas foi $30 \%$ inferior às propagadas por estaquia e similar à das propagadas por sementes.

As plantas do clone GA-2, propagadas por enxertia e estaquia, não diferiram entre si quanto ao ataque de doenças (Tabela 2), mas foram muito menos afetadas que as propagadas por sementes. Estas plantas expressaram certo grau de resistência às doenças, porém esperava-se menor incidência de podridão de raízes (Fusarium solani) nas plantas enxertadas, tendo em vista a suposta resistência do $P$ nitida a doenças causadas por patógenos do solo. Em várias plantas, a infecção por $F$. solani ocorreu no ponto de inserção do enxerto no porta-enxerto, pelo fato de a enxertia ter sido efetuada a menos de $20 \mathrm{~cm}$ de altura em relação ao coleto. Embora as plantas do clone GA-2 fossem mais tolerantes à antracnose, essa doença, favorecida pelo período chuvoso prolongado, foi limitante, impedindo a análise do comportamento das plantas enxertadas por um período mais longo.

\section{CONCLUSÕES}

1. A propagação de maracujazeiro-azedo por enxertia em estacas enraizadas de $P$. nitida e por estaquia é tecnicamente viável. No entanto, são necessários mais estudos sobre estes tipos de propagação, bem como das espécies com potencial para porta-enxerto.

2. As plantas propagadas por enxertia e por estaquia foram menos afetadas pelas doenças, mas as propagadas por estaquia foram as mais produtivas.

3. A propagação de plantas superiores de maracujá por estaquia contribui para melhorar o grau de resistência a doenças, melhorar a qualidade dos frutos e aumentar a produtividade.

\section{REFERÊNCIAS}

BRAGA, M. F.; JUNQUEIRA, N.; FALEIRO, F. G.; ALMEIDA, D.A; CABRAL, G. A.; SOUSA, A. A.T. C de; RESENDE, A. M de. Desempenho agronômico de um clone de maracujazeiro-azedo propagado por estaquia e enxertia em estacas enraizadas de um híbrido F1 de Passiflora edulis f. flavicarpa comercial x P. setacea. In: CONGRESSO BRASILEIRO DE FRUTICULTURA, 18., 2004, Florianópolis - SC. Anais... Jaboticabal: SBF, 2004. CD-ROM

CHAVES, R.C.; JUNQUEIRA, N.T.V.; MANICA, I.; PEIXOTO, J.R.; PEREIRA, A.V.; FIALHO, J.F. Enxertia de maracujazeiro-azedo em estacas herbáceas enraizadas de espécies de passifloras nativas. Revista Brasileira de Fruticultura, Jaboticabal, v.26, n.1, p.120 123,2004

FISCHER, I.H. Seleção de plantas resistentes e de fungicidas para o controle da "morte prematura" do maracujazeiro, causada por Nectria hematococca e Phytophthora parasitica. 2003. 48f. Dissertação (Mestrado) - Escola Superior de Agricultura Luiz de Queiroz, Universidade de São Paulo, Piracicaba, 2003.

JUNQUEIRA, K.P.; FALEIRO, F.G.; RAMOS, J.D.; BELLON, G; PAULA, M.S.; JUNQUEIRA, N.T.V.; BRAGA, M.F. Variabilidade genética de acessos de maracujá-suspiro (Passiflora nitida Kunth.) com base em marcadores moleculares. In: REUNIÃO TÉCNICA DE PESQUISAEM MARACUJAZEIRO, 4., 2005, Planaltina. Trabalhos 
apresentados... Planalatina: Embrapa Cerrados, 2005. p.122-127.

MALDONADO, J.F.M. Utilização de porta-enxertos do gênero Passiflora para maracujazeiro-amarelo (P. edulis f. flavicarpa). Revista Brasileira de Fruticultura, Cruz da Almas, v.13, n.2, p.5154, 1991.

MELETTI, L.M.M.; BRUCKNER, C. H. Melhoramento genético. In: BRUCKNER, C. H.; PICANÇO, M.C. (Ed.). Maracujá: tecnologia de produção, pós-colheita, agroindústria, mercado. Porto Alegre: Cinco Continentes, 2001. p. 345-385.

MENEZES, J.M.T.; OLIVEIRA, J.C.; RUGGIERO, C.; BANZATO, D. A. Avaliação da taxa de pegamento de enxertos de maracujá-amarelo sobre espécies tolerantes à "morte prematura de plantas". Científica, São Paulo, v.22, n.1, p.95-104, 1994.

NOGUEIRA FILHO, G.C. Enxertia hipocotiledonar de maracujazeiroamarelo em espécies de passifloras silvestres. 2003. 119f. Tese (Doutorado em Fitotecnia) - Faculdade de Ciências Agrárias e Veterinárias, Universidade Estadual Paulista, Jaboticabal, 2003.

NOVAES, Q. S.; REZENDE, J. A. M. Possível aplicação do DAS-ELISA indireto na seleção de maracujazeiro tolerante ao "Passionfruit Woodiness Virus”. Fitopatologia Brasileira, Brasília, v. 24, n. 1, p. 76-79, 1999.
OLIVEIRA, J.C.; NAKAMURA, K.; CENTURION, M.A.P.C.; RUGGIERO, C.; FERREIRA, F.R.; MAURO, A.O.; SACRAMENTO, C.K. Avaliação de Passifloráceas quanto à morte prematura de plantas. In.: CONGRESSO BRASILEIRO DE FRUTICULTURA, 13., 1994, Salvador-BA. Resumos... Salvador, BA: SBF, 1994. v.3. p.827. (Resumo, 347).

RONCATTO, G.; OLIVEIRA, J. C.; RUGGIERO, C.; NOGUEIRAFILHO, G. C.; CENTURION, M. A. P. C.; FERREIRA, F. R. Comportamento de maracujazeiros (Passiflora spp.) quanto à morte prematura. Revista Brasileira de Fruticultura, Jaboticabal, v.26, n.3, p.552$554,2004$.

RUGGIERO, C. Situação da Cultura do Maracujazeiro no Brasil. Informe Agropecuário, Belo Horizonte, v.21, n.206, p.5-9, 2000.

SÃO JOSÉ, A.R. Propagação do Maracujazeiro. In: SÃO JOSÉ, A.R. (Ed.). A cultura do maracujá no Brasil. Jaboticabal: FUNEP, 1991. P.25-43.

SIQUEIRA, D. L. de; PEREIRA, W.E. Propagação. In: BRUCKNER, C.H.; PICANÇO, M.C. (Ed.). Maracujá: tecnologia de produção, póscolheita, agroindústria, mercado. Porto Alegre: Cinco Continentes, 2001.p. $85-137$ 